\title{
TREATMENT OF COLLAPSIBLE SOILS WITH GRANULATED BLAST FURNACE SLAG AND CALCINED EGGSHELL WASTE
}

\author{
Souhila ADJABI*, Mohamed Salah NOUAOURIA, Wafa DJEBABLA \\ University of 8 May 1945, Guelma, Algeria
}

\begin{abstract}
In order to meet environmental and socio-economic challenges, the recycling of waste to be used in the treatment of geotechnical problems is one of the main ways of preserving the environment with a lower economic value. The objective of this experimental work is to improve the characteristics and to study the mechanical behaviour of collapsible soil treated with a new hydraulic stabilizer composed of Crushed Granulated Blast Furnace Slag (CGBS) active by Eggshell Waste (CES). The specimens were mixed with stabilizer content, varying from 0 to $15 \%$ in mass, with an initial water content of 4,6 and $8 \%$ respectively. in mass. Oedometer apparatus was used to study the addition of new hydraulic stabilizer effect on the Collapse Potential. Triaxial tests are also conducted to determine the shear strength parameters (cohesion and internal friction angle) of this treated soil. The results of this research study show that the mechanical properties of the treated collapsible soil were significantly improved. An appreciable reduction in the collapse potential is observed. The addition of $15 \%$ of this new stabilizer with initial water content of $4 \%$ under a compaction of 60 blows/ layer is capable of increasing internal friction angle and cohesion. It can be concluded from this study that the mixture of granulated slag and calcined eggshell can be used as an effective treatment of collapsibility phenomenon at low cost while protecting the environment from industrial waste.
\end{abstract}

\footnotetext{
*Corresponding author: Civil Engineering and Hydraulic Laboratory, University of 8 May 1945, Guelma, Algeria, e-mail: adjabi.souhila@univ-guelma.dz
} 
Keywords: shear strength, cohesion, internal friction angle, blast furnace slag, calcined eggshell, collapsible soil, compaction energy

Abbreviations

CES: Calcined eggshell

CGBS: Crushed Granulated Blast Furnace Slag

C-S-H: calcium silicate hydrate

C-A-H: calcium aluminate hydrate

EDM: Energy Dispersive X-ray Microanalysis

SEM: Scanning Electron Microscopy

$\mathrm{CaO}$ : calcium oxide

$\tau$ : shear strength

$\sigma:$ normal strength

c: cohesion

$\varphi$ : internal friction angle

UU: unconsolidated undrained

CP: Collapse potential

Ec: Compaction Energy

w: water content

UTS: Untreated Soil

TS: Treated Soil

\section{INTRODUCTION}

The importance of waste recycling lies in many aspects, such as environmental, economic, social and health aspects. On the environmental side: the waste recycling process contributes mainly to reducing the percentage of pollution of all kinds, by reducing the accumulation of waste which contributes significantly to environmental pollution, due to the emission of polluted gases and toxic elements into the air, water and soil, with the exception of its role in reducing the pressure on waste collection and dumping sites, which helps to provide significant financial resources, as the establishment of sanitary landfills requires the presence of considerable financial resources, in addition to reducing the costs of collection Transfer and disposal of waste.

The decomposition of waste leads to the release of the toxins it contains into water sources, whether underground or surface water, polluting the soil and emitting unpleasant odours. It also hurts to look at the heaps of waste that cause the tyranny of the landscape and distort the aesthetic value that people enjoy.

In another context, the most frequent type of collapsible soil is hydro-compactive soils, who occurs in arid and semi-arid climates. This term indicates that the presence or addition of water to the soil becomes wet when it is associated with soil compaction and indicates a driving mechanism. The characteristics as open 
structure, high porosity, and low inter-particle bond strength. The soils particles are originally loosely packed. Rather, the grains are stacked precariously. This structural fabric of the soil is preserved intact by the presence of silt and clay bonds between the grains, other binding materials, and the soil absorption pressure, where the common point between these elements is their sensitivity to water. It is known as the meta-stable state despite being solid in a dry state, but the addition of water will cause rapid decomposition, softening, diffusion or dissolution of the "sticky" bonds. The larger soil particles shear against each other and move to reorient themselves into a denser arrangement. This relatively rapid densification of the soil results in a net loss of soil sediment volume that appears at the soil surface as collapse or settlement.

Collapsible soils are sensitive to suddenly settling when they are wetted and loaded. Therefore, buildings erected on these types of soils are faced to a risk of collapse. Nowadays, different soil reinforcement and stabilization techniques are used to improve the geotechnical characteristics of these soils, either by through the addition of cementitious agents or by the inclusion of discrete elements; arbitrarily distributed like fibers. Reinforced and stabilized soils can be considered as composite materials that result from the combination and improvement of the properties of its individual components.

Since the beginning of the 1970s, several researchers have studied stress-strain characteristics of reinforced soil using triaxial, direct shear, and plane strain tests, the most of this research based on waste recycling.

A great deal of experience investigation has been carried out in this field. Settlements of Bearing Plates on Loess are studied [1]. Treatment of the collapsible soil with APC cements [2], and with bituminous was applied in-situ at a depth of less than $4 \mathrm{~m}$ [3]. Many investigators have used various types of fibers under different test conditions in order to assess the effect of randomly distributed fiber reinforcement on the response of sandy and sand cleyey soils $[4,5]$. There is another research that evaluates the performance of the silty sand layer reinforced with fiber and treated with fly ash [6]. The effect of randomly distributed palm empty fruit fiber on the strength of reinforced silty sand was evaluated [7]. Some collapsible soils were treated with salts [8].The influence of the addition of paper stripes on the modulus of elasticity of the foundation soil was also investigated [9]. Some of research studies on the effect of reinforced soils with randomly included papyrus fiber [10]. The results of this research indicated that the compressive and shear strength of cemented sand has been significantly increased due to fiber reinforcement.

Mohamed et al. [11] used the sulfur cement to treat collapsible soils. Some researchers reviewed and evaluated most of the well-known collapse identifying criteria. They have established a new method that allows rapid and safe prediction 
of collapse [12]. A new technique generation to treat the soil is alkaline activation [13], and the use of geopolymer [14].

Clayey soil stabilization was performed using shredded rubber tires [15], and with grouting technique [16]. Randomly distributed fibers PET was also studied [17]. coir and synthetic fiber were also used to treinforced the collapse soil [17]. Das et al. [18] presented in their study on the effect of osmotic aspiration, the behaviour of collapse and due to the increase in macroporosity and the matrix aspiration of porous fluid the collapse of compacted clay sand increases [18]. The stabilization of collapsible soil by asphalt was also investigated [19]. Experimental tests were also undertaken on samples treated with XPS-cement in order to reduce the collapse potential [20].

Subsequently sisal and PET fibers were used to reinforce collapsible soil [21]. Some researchers have studied the influence of fiber inclusion, which decreases sand expansion and increases shear strength, permeability and porosity due to the lack of a potential barrier between solid particles [22].

To enhance the mechanical properties of loess soil, they used the technique of addition of $\mathrm{SiO}_{2}$ nanoparticles [23]. Another study showed that the additional load and maximum negative skin friction due to the compacting effect of the battered pile, has a negative correlation with the amount of collapse, also the collapsibility rate of loess is affected by natural moisture content and dry density; hence collapse can be improved by an additional loading and a pre-wetting to reduce the harmful effect of the negative friction of the skin on the pile foundations, these results are carried out by Xing et al. [24]. Studies evaluate the treatment of this type of soil with a mixture of bentonite and cement [25] or with natural pozzolan and slag mixture [26].

In order to achieve sustainable development, equilibrium must be found between the environmental, economic, social and technological systems and contribute to the maximum growth of these systems. The question is what will be the contribution of geotechnical engineering to make for reducing environmental pollution. The aim of this article is to study the efficiency of using blast furnace slag and eggshells waste and exploiting them to solve geotechnical problems such as soil collapse, and to study also the mechanical behaviour of this treated soil, taking into account the safety and economic side on the one hand and the ecological side on the other hand where available materials have been used. Inexpensive and harmful to nature. So the process of recycling this waste for the benefit of civil and geotechnical engineering as a reliable solution achieves many objectives at the same time as treating soil collapses and improving its resistance as it becomes suitable for construction. As well as the protection of the environment against pollution, for this effect it is used as mixture of $15 \%$ of Crushed Granulated Blast Furnace Slag (CGBS) and 85\% of Calcined Eggshell 
Waste (CES). Different contents of this mixture were respectively used, namely: $5 \%, 10 \%$ and $15 \%$, under Oedometer and triaxial loading conditions. The specific objectives of the present work are to determinate the effect of treatment content, water content and compaction energy, on the collapse potential and the intrinsic parameters of reconstituted collapsible soil.

\section{MATERIALS}

\subsection{Soil}

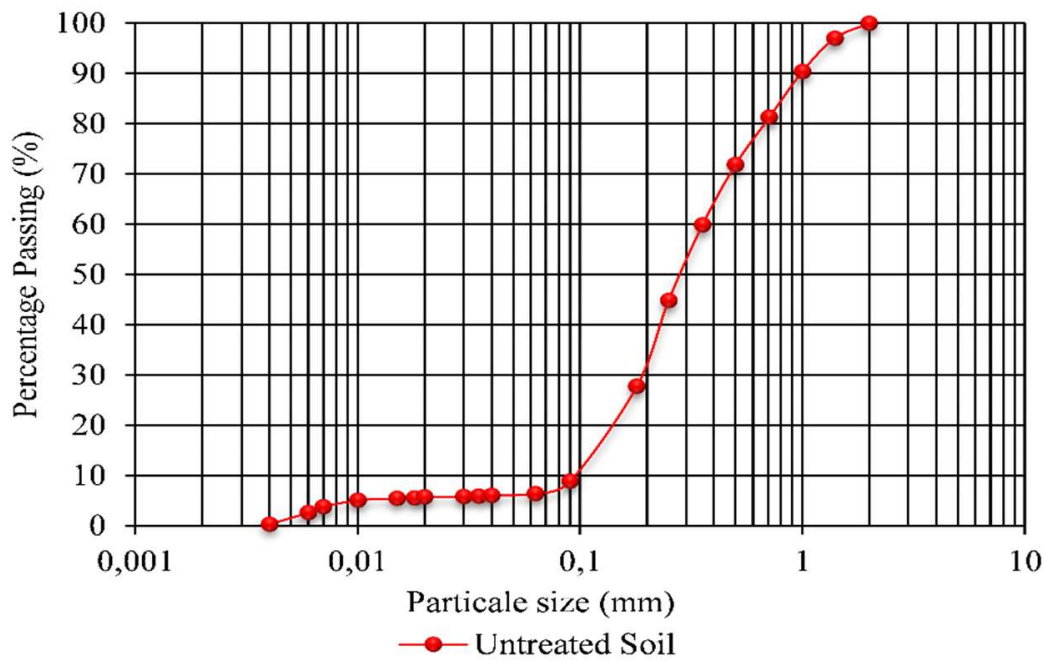

Fig.1. Particle size distribution curve of reconstituted soil

In this investigation, the reconstituted soil is a mixture of sand and kaolin, with the formula of $\mathrm{Al}_{2} \mathrm{O}_{3} .2 \mathrm{SiO}_{2} .2 \mathrm{H}_{2} \mathrm{O}$, in proportions of $25 \%$ which is the optimum content of Kaolin giving the maximum potential collapse [27, 16, 21] , with the grain size distribution curve and the chemical composition are illustrated in fig. 1. and table1 and table 2 respectivelly.

Table 1. Chemical composition of the reconstituted soil

\begin{tabular}{|c|c|c|c|}
\hline Element & \% of mass & Atomic \% & Total Intensity \\
\hline C K & 11.89 & 17.33 & 19.41 \\
\hline O K & 58.53 & 64.04 & 427.78 \\
\hline AlK & 14.14 & 9.18 & 264.37 \\
\hline SiK & 14.46 & 9.01 & 257.77 \\
\hline K K & 0.98 & 0.44 & 11.90 \\
\hline
\end{tabular}



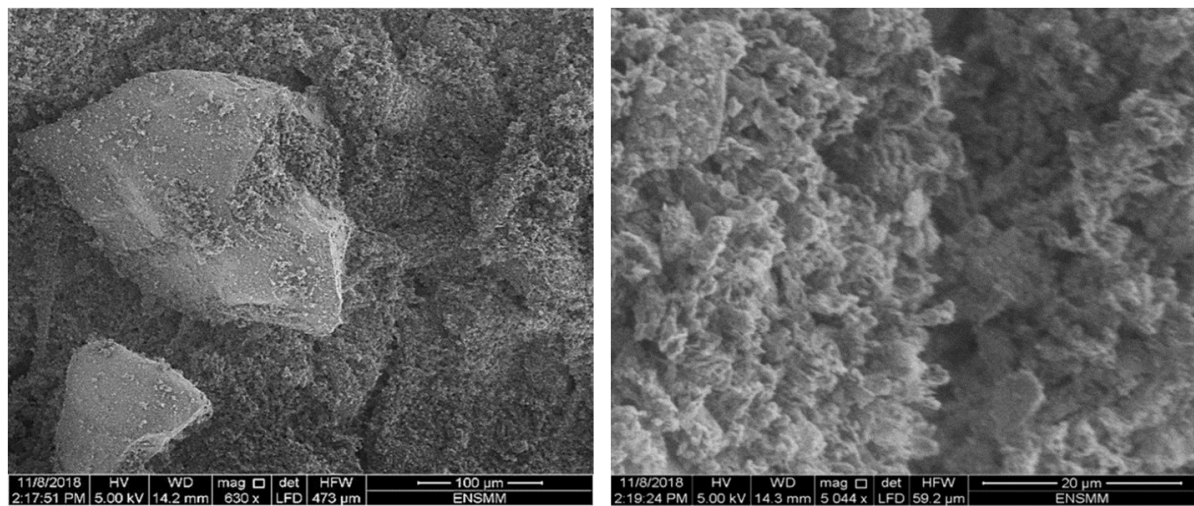

Fig.2. Scanning electron micrograph of clayey sand sample

In fig. 2, the microstructure examination shows that the sample in both magnifications presents an "open structure".

Table 1. Chemical composition of the reconstituted soil

\begin{tabular}{|c|c|c|}
\hline Type Soil & Characteristics & Value \\
\hline Sand $(<2 \mathrm{~mm})$ & Coefficient of uniformity, Cu & 5.27 \\
& Coefficient of curvature, Cc & 1.46 \\
& Sand equivalent, Es (\%) & $80 \%$ \\
& Specific gravity, Gs & 2.65 \\
& & \\
\hline Kaolin & Liquid limit, W1 (\%) & 60 \\
& Plastic limit, Wp (\%) & 45 \\
& Plasticity Index IP (\%) & 15 \\
& Specific gravity, Gs & 2.61 \\
& & \\
\hline Reconstituted & & 3.74 \\
& & 1.07 \\
& Coefficient of uniformity, Cu & 17.6 \\
& Coefficient of curvature, Cc & 14.31 \\
& Liquid limit, W1 (\%) & 77 \\
& Plastic limit, Wp (\%) & 2.63 \\
& Sand equivalent, Es (\%) & 1.61 \\
& Specific gravity, Gs & \\
& Dry density, $\rho d\left(\mathrm{~g} / \mathrm{cm}{ }^{3}\right)$ & \\
& & \\
& &
\end{tabular}




\subsection{Treatment materials}

The materials used for the treatment of the soil in this study are:

The eggshell was obtained from white and brown eggs in a semi-crushed state, it is then washed with tap water to remove odor and all types of contaminants, and it was dried in the oven for 24 hours at a temperature of $40^{\circ} \mathrm{C}$. Then, it was calcined in a muffle furnace, at $900^{\circ} \mathrm{C}$ for 2 hours to allow calcium carbonate to be transformed completely into calcium oxides, [28, 29, 30]. Using the MicroDeval apparatus, calcined eggshell was finely crushed into powder. Then, the product was identified by adequate physiochemical techniques such as SEM and EDM. The structure microscopy of calcined and intact eggshell is illustrated in Fig. 3. According to the EDM analysis shown in Table 2, the chemical properties of calcined eggshell is similar to that of lime, which is the main composition of $\mathrm{CaO}$ where its contents in calcined eggshell are about $92.02 \%$ as shown in table 3 . This high quantity of calcium oxides contain in calcined eggshell show that it can interact with CGBS and form a cementitious material.

The GGBS has been the subject of several investigations[31, 32]. This GGBS was supplied by the Metallurgical Unit of El Hadjar, in Annaba city. It was dried in the oven and crushed with the Micro Deval machine similarly as calcined eggshell, in order to reach fineness around $4000 \mathrm{~cm}^{2} / \mathrm{g}$ [32] .

Table 3. Chemical and physical properties of additives

\begin{tabular}{|c|c|c|}
\hline Composition or property & CES (\%) & CGBS (\%) \\
\hline $\mathrm{CaO}$ & 92.02 & 42,71 \\
\hline $\mathrm{MgO}$ & 1.21 & 2,25 \\
\hline $\mathrm{SiO}_{2}$ & 0.41 & 41,07 \\
\hline $\mathrm{Na}_{2} \mathrm{O}$ & 0.19 & 0,25 \\
\hline $\mathrm{SO}_{3}$ & 0.12 & 0,28 \\
\hline $\mathrm{Al}_{2} \mathrm{O}_{3}$ & 0.11 & 9,06 \\
\hline $\mathrm{K}_{2} \mathrm{O}$ & 0.09 & 0,83 \\
\hline $\mathrm{Fe}_{2} \mathrm{O}_{3}$ & 0.02 & 3,31 \\
\hline Specific surface $\left(\mathrm{cm}^{2} / \mathrm{g}\right)$ & 2954 & 2985 \\
\hline
\end{tabular}



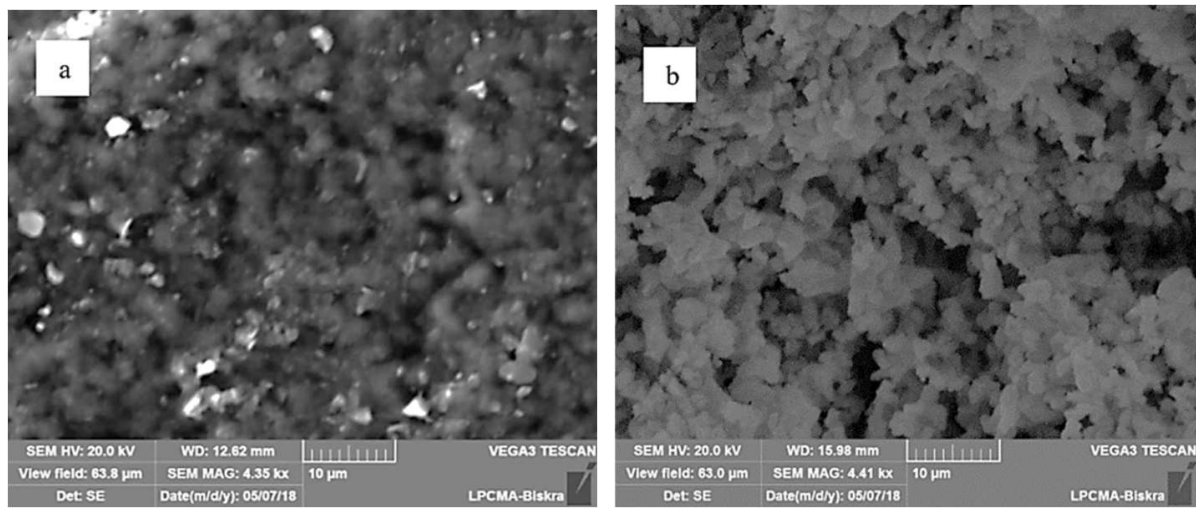

Fig.3. Microstructure transformation of eggshell: a) before calcination, b) after calcination

\section{SPECIMEN PREPARATION AND TESTING PROCEDURES}

According to the tests findings that show the influence of the Kaolinite content on the collapse potential, it should be noted that the Kaolinite content of $25 \%$ has given maximum collapse potential, as presented in fig. 4. These findings affirm the observations made by Lawton et al. [29], whitch reports that the maximum collapse is obtaned with a clay content between $10 \%$ and $40 \%$ these results in good agreement with the results obtained by Nouaouria and Adjabi [34, 21] who indicated that the maximum collapse potential was gated with an optimal content of approximately $25 \%$ of Kaolinite.

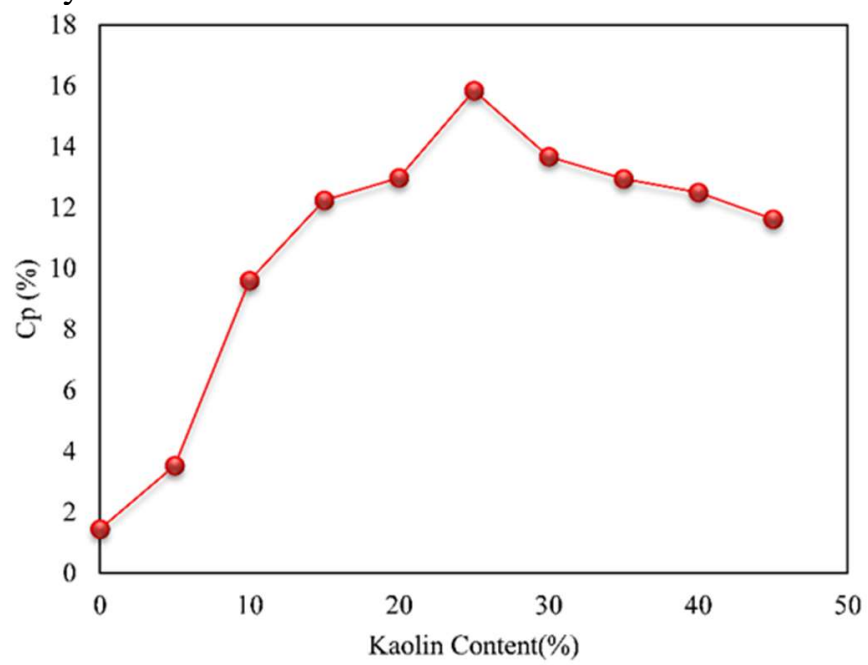

Fig. 4. Effect of the Kaolinite content on the collapse potential 
The reconstituted soil is well mixed using hands with $5 \%, 10 \%$ and $15 \%$ of treatment materials to study the influence of treatment content on the collapse potential and an water content of $4 \%, 6 \%$ and $8 \%$ to determine the effect of water content on the parameter of treated collapsible soil , these simples were submitted under different energy of compaction such as 20,40 and 60 blows by layer respectively using laboratory designed compaction device [9]. In the first set of tests, the homogeneous sample is placed into the Oedometer ring and compacted with different values of compaction energy as illustrated in table 3 . The compressive tests were performed according to the Jennings and Knight procedure [35].

Triaxial tests were executed according to the testing standards established by ASTM D2850 [36]. Unconsolidated undrained tests (UU) were performed on the cylindrical specimens for the treated samples of $50 \mathrm{~mm}$ in diameter and $100 \mathrm{~mm}$ in height. The samples were prepared at the same conditions as for Oedometer tests. The samples are subjected to different normal pressures $(\sigma 3=100,200,300$ $\mathrm{kPa})$ respectively to obtain the shear strength parameters $(\mathrm{c}$ and $\varphi)$.

Furthermore, Scanning Electron Microscope images were performed to examine the new compounds created by reaction between the stabilizer and the soil particles.

The series of the performed tests and the proportions of the various additives are illustrated in Table 4.

Table 4. Various additives used the treated soil

\begin{tabular}{|c|c|c|c|}
\hline Tests & $\begin{array}{c}\text { CES+ CGBS } \\
(85 \%+15 \%)\end{array}$ & $\begin{array}{l}\text { Water content } \\
(\mathrm{w} \%)\end{array}$ & $\begin{array}{c}\text { Number of blows/ } \\
\text { layer }\end{array}$ \\
\hline \multirow{3}{*}{$\begin{array}{c}\text { Untreated soil } \\
\text { (Sand+ kaolin) }\end{array}$} & \multirow[t]{3}{*}{0} & 4 & $20,40,60$ \\
\hline & & 6 & $20,40,60$ \\
\hline & & 8 & $20,40,60$ \\
\hline \multirow[t]{3}{*}{$\begin{array}{l}\text { Soil treated with } \\
\text { (CES+ CGBS) } \\
(85 \%+15 \%)\end{array}$} & 5 & $\begin{array}{l}4 \\
6 \\
8\end{array}$ & $\begin{array}{l}20,40,60 \\
20,40,60 \\
20,40,60\end{array}$ \\
\hline & 10 & $\begin{array}{l}4 \\
6 \\
8 \\
\end{array}$ & $\begin{array}{l}20,40,60 \\
20,40,60 \\
20,40,60 \\
\end{array}$ \\
\hline & 15 & $\begin{array}{l}4 \\
6 \\
8\end{array}$ & $\begin{array}{l}20,40,60 \\
20,40,60 \\
20,40,60 \\
\end{array}$ \\
\hline
\end{tabular}




\section{RESULTS AND DISCUSSIONS}

\subsection{Oedometer tests}

\subsubsection{Influence of initial water content on Collapse Potential (CP) at different compaction energy}

To improve the characteristics of the reinforced soil with CES and CGBS, an amount of distilled water was added in three different proportions such as: 4, 6 and $8 \%$ respectively. Samples were simply compacted under different values of energy. The results are illustrated in Fig. 5.

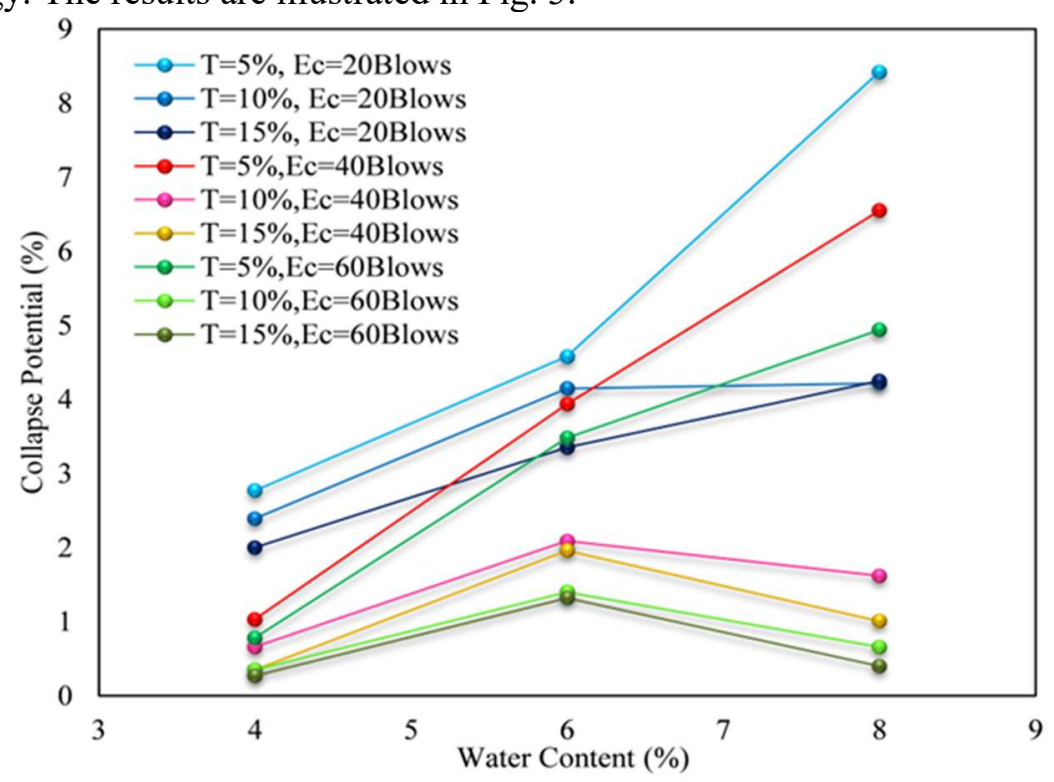

Fig.5. Influence of initial water content on the collapse potential

(CP)

It can be noted that the collapse potential is clearly affected by the initial water content. With the energy of compaction of 20 blows/layer, the collapse potential increases with increasing the water content, this behaviour is due the loose state of the soil. The same behaviour was noticed with the low ratio of the additives even with the energy of 40 and 60 blows/layer. Taking into account $\mathrm{T}=10 \%$ and $\mathrm{T}=15 \%$, the energy of 40 and 60 blows/layer revealed an optimum water content of $6 \%$ corresponding to maximum values of $\mathrm{CP}$. Based on the energy of compaction, it can be then concluded that the collapse potential is influenced by the initial water content. These results are in good agreement with those obtained by Abbeche et al. and Bellil et al. $[1,15]$. 


\subsubsection{Influence of treatment content on the collapse potential}

The effect of treatment or stabilizer content on the collapse potential, of treated soil is shown in Fig. 6. It is clearly seen that the CP decreases with increasing the content of the stabilizer. For water content $\mathrm{w}=4 \%$, it is importand to notice that a reduction of the CP from $84.34 \%$ to $94.67 \%$ between the untreated and treated soils, where $\mathrm{CP}=12.77 \%$ for a compaction energy of 20 blows/layer in the untreated soil. In contrast, a CP of $0.27 \%$ was recorded with $15 \%$ of stabilizer and $\mathrm{Ec}=60$ blows/layer. This collapse potential is then considered as no problem according to Jennings and Knight Classification [35]. For a water content of $\mathrm{w}=6 \%$, the $\mathrm{CP}$ varied from $10.67 \%$ for untreated soil and $\mathrm{Ec}=20$ blows to $\mathrm{CP}=$ $3.35 \%$ for treatment content of $15 \%$.

The results show that the influence of the stabilizer is almost the same as the lime treatment as indicated by Abbeche et al. [37] and Firoozfar et al. [38]. Then, according to the test results and the chemical composition as shown in Fig. 10 which shows that the main component of the stabilizer is calcium, the new stabilizer is comparable with lime and it reacts in the same way in the soil as lime.

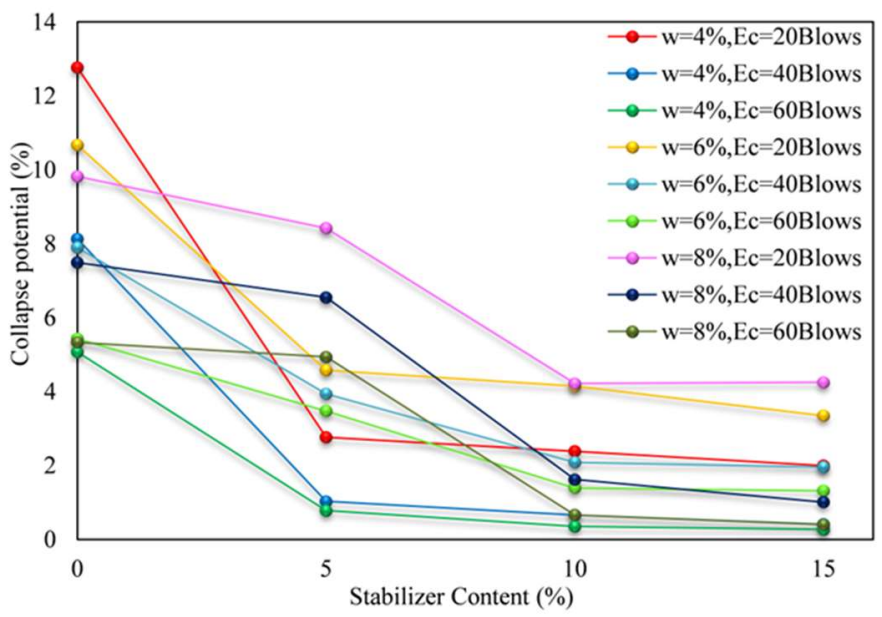

Fig. 6. Effect of Stabilizer content on the Collapse Potential at different compaction energy

However, for $15 \%$ of stabilizer and $\mathrm{Ec}=60$ blows, a decrease in $\mathrm{CP}$ was noticed from $75.69 \%$ to $68.6 \%$, the soil treated with this amount of stabilizer is considered to cause moderate trouble problems. It is also pointed out that for $\mathrm{w}=8 \%$, the $\mathrm{CP}$ varied from $9.82 \%$ for untreated soil and $\mathrm{Ec}=20$ blows, to a value of $0.4 \%$ for an addition of $15 \%$ and $\mathrm{Ec}=60 \mathrm{blows}$, based on Jennings and Knight Classification [26] in this part the treated soil is indexed from trouble to no 
problem. Generally, these results are better than those obtained by Al Shaba et al. [39], where they obtained a minimum of $\mathrm{CP}=5.5 \%$. Ziani et al. [26] obtained the minimum of $\mathrm{CP}=0.84 \%$, versus the results of this study which is $\mathrm{CPmin}=0.27 \%$. This decrease in CP proves that there is an improvement in the physical and chemical properties in the matrix of treated soil. It can be explained that due to the chemical reaction between $\mathrm{CaO}$ from calcined eggshell (CES) and $\mathrm{Al}_{2} \mathrm{O}_{3}$, $\mathrm{Si}_{2} \mathrm{O}_{3}$ from GGBS and Kaolin, these results are in a good agreement with those obtaned by Iranpour and Haddad [40] who recommended to improve the strength of clay and silty bonds as well as cementing elements to have a stable soil structure and reduce the collapse potential $(\mathrm{CP})$.

\subsubsection{Influence of energy compaction on the collapse potential CP}

As shown in Fig. 7, it should be noted that the collapse potential reduces with increasing compaction energy for different contents of water and stabilizer. The soil treated with various additions of stabilizer contents, such as $5 \%, 10 \%$ and $15 \%$, and compacted under 60 blows/layer presented a reduction in CP values of about $76 \%, 92 \%$ and $95 \%$ respectively. The final $\mathrm{CP}$ of treated samples is $1.32 \%$, $0.4 \%$ and $0.27 \%$, as shown in fig. 7 . It can be concluded that there is a significant decrease in the collapse potential when the addition of stabilizer and the compaction energy are coupled. It should be noted that the treatment of soil with CES+GGBS mixture content of $15 \%$ has decreased the collapse potential to $0.4 \%$ for $\mathrm{w}=8 \%$ and to $\mathrm{CP}=0.27 \%$ for $\mathrm{w}=4 \%$ with a compaction energy corresponding to $60 \mathrm{blows} /$ layer however, the minimum collapse potential obtained is now considered to cause no problem according to Jennings and Knight classification [35]. This reduction in $\mathrm{CP}$ is due to the effect of both compaction and stabilizer, which lead to a dense state of this soil when it is loaded and wetted. 


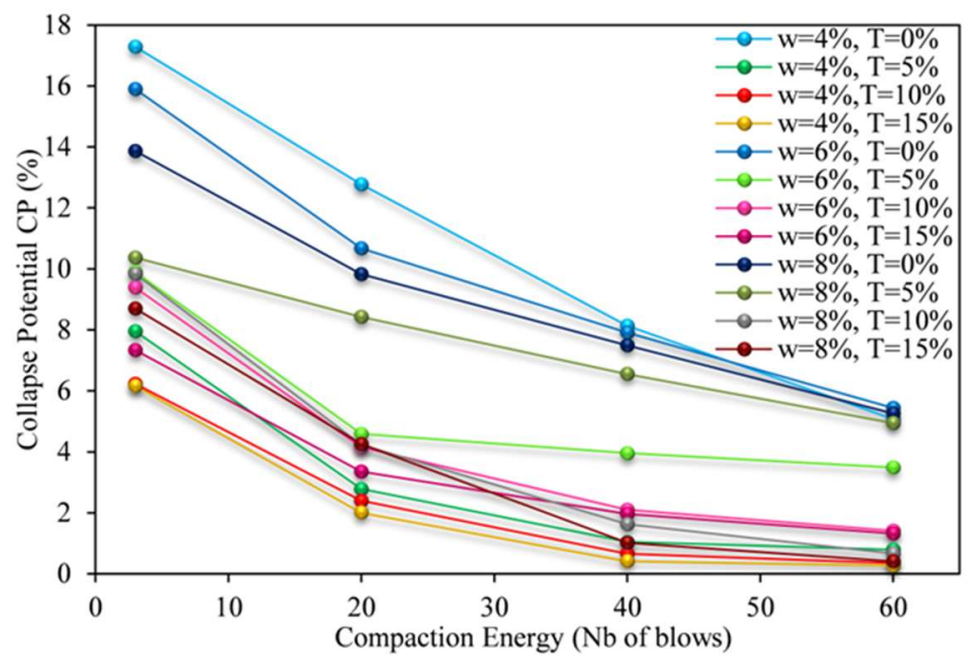

Fig.7. Effect of compaction energy on the collapse potential at different water content

As shown in Fig. 7, it should be noted that the untreated soil, despite being compacted, has a high collapse factor, but once the stabilizer is added, the value of the collapse potential clearly decreases as the amount of stabilizer and the compaction energy increase, which might be due to the collapse potential is inversely proportional to the amount of stabilizer and the compaction energy. These findings are in good agreements with those obtained by Al Shaba et al. [39]. Compacted soil at energy of 3 blows/layer still have an open structure with a relatively high void ratio, facilitating the migration of fine particles from one level to another in the soil sample. However, compaction with 60 blows/layer makes the soil grains closer together and reduces the voids between them, making the soil state denser. Therefore, the destruction of intergranular bonds and movement of fine particles or grains leaching become relatively difficult. This can be confirmed by the results of Kinuthia et al., Abbeche et al., Bahloul et al. [1, 12, 27] and Bellili et al. [25].

\subsection{Triaxial tests}

\subsubsection{Effect of treatment on the behaviour of the collapsible soil}

The results of shear strength parameters of unconsolidated undrained (UU) tests on treated and non-treated soils are summarized in table 5. It is clear that the 
variation of the internal friction angle $(\varphi)$ and the cohesion $(C)$ depends on the amount of stabilizer (CES-CGBS) at different water contents and compaction energy. It can be indicated that the cohesion increases with increasing both stabilizer and compaction energy, comparing with those of untreated soil. This increase in soil cohesion is due to cementitious bounds (C-S-H) which is produced from reaction between $\mathrm{CaO}$ of calcined eggshell and soil particles. So, this used stabilizer has a significant effect on the cohesion (C), keeping the internal friction angle almost unchanged.

Table 5. Shear strength parameters of treated soil

\begin{tabular}{|l|l|l|l|l|l|l|l|l|l|l|l|l|}
\hline $\begin{array}{l}\text { Compaction } \\
\text { Energy (Ec) }\end{array}$ & \multicolumn{3}{l}{3 Blows/layer } & \multicolumn{3}{l|}{20 Blows/layer } & \multicolumn{3}{l|}{40 Blows/layer } & \multicolumn{3}{l|}{60 Blows/layer } \\
\hline $\begin{array}{l}\text { Initial water } \\
\text { content w (\%) }\end{array}$ & 4 & 6 & 8 & 4 & 6 & 8 & 4 & 6 & 8 & 4 & 6 & 8 \\
\hline UTS & & & & & & & & & & & & \\
\hline C (Kpa) & 15,08 & 16,11 & 18,32 & 21,2 & 21,98 & 23,41 & 24,49 & 26,01 & 29,21 & 35,08 & 35,33 & 36,1 \\
\hline$\varphi\left(^{\circ}\right)$ & 25,61 & 24,41 & 25,3 & 26,53 & 26,87 & 26,09 & 29,77 & 27,92 & 27,06 & 33,08 & 29,3 & 28,52 \\
\hline $\begin{array}{l}\text { TS (5\%) } \\
(85 \% \text { CES+ } \\
15 \% \text { CGBS) }\end{array}$ & & & & & & & & & & & & \\
\hline C (Kpa) & 15,33 & 18,64 & 17,81 & 31,54 & 33,32 & 18,81 & 33,55 & 37,36 & 45,04 & 40,62 & 39,28 & 51,68 \\
\hline$\varphi\left(^{\circ}\right)$ & 25,09 & 24,66 & 22,2 & 25,53 & 27,18 & 19,84 & 30,33 & 23,39 & 18,74 & 30,8 & 30,86 & 17,14 \\
\hline $\begin{array}{l}\text { TS (10\%) } \\
(85 \% \text { CES+ } \\
15 \% \text { CGBS) }\end{array}$ & & & & & & & & & & & & \\
\hline C (Kpa) & 18,25 & 16,44 & 12,14 & 25,25 & 37,16 & 47,67 & 27 & 44,66 & 50,59 & 29,77 & 51,25 & 51,93 \\
\hline$\varphi\left(^{\circ}\right)$ & 22,69 & 23,6 & 24,97 & 26,19 & 28,57 & 14,92 & 30,68 & 29,58 & 17,79 & 33,04 & 27,06 & 19,95 \\
\hline $\begin{array}{l}\text { TS }(15 \%) \\
(85 \%\end{array}$ & & & & & & & & & & & & \\
$\begin{array}{l}\text { CES+15\% } \\
\text { CGBS) }\end{array}$ & & & & & & & & & & & & \\
\hline C (Kpa) & 25,51 & 17,49 & 15,58 & 27,6 & 50,3 & 53 & 31,18 & 53,41 & 54,27 & 34,6 & 55,15 & 55,58 \\
\hline$\varphi\left(^{\circ}\right)$ & 21,75 & 23,58 & 24,37 & 26,18 & 13,79 & 21,19 & 30,55 & 17,91 & 21,14 & 27,4 & 17,38 & 24,06 \\
\hline
\end{tabular}

According to the Fig.8, it can be observed that the shear stress increases with increasing the confining pressure, the stabiliser content and the compaction energy. When the initial water content $\mathrm{w}=4 \%$ and for a confining pressure of 100 $\mathrm{kPa}$ and a stabilizer content of $15 \%$,the shear stress varies from $\tau \mathrm{min}=275 \mathrm{kPa}$ with 20 blows/layer to $\tau \max =421 \mathrm{kPa}$ with 60 blows/layer. For a confining 
pressure of $200 \mathrm{KPa}$, and stabilizer content $15 \%$, the shear stress varies from $\tau$ $\min =453 \mathrm{kPa}$ with 20 blows/layer to $\tau \max =664 \mathrm{kPa}$ with 60 blows/layer. For a confining pressure of $300 \mathrm{KPa}$, and stabilizer content $15 \%$, the shear stress varies from $\tau \min =670 \mathrm{kPa}$ with 20 blows/layer to $\tau \max =945 \mathrm{kPa}$ with $60 \mathrm{blows} /$ layer.

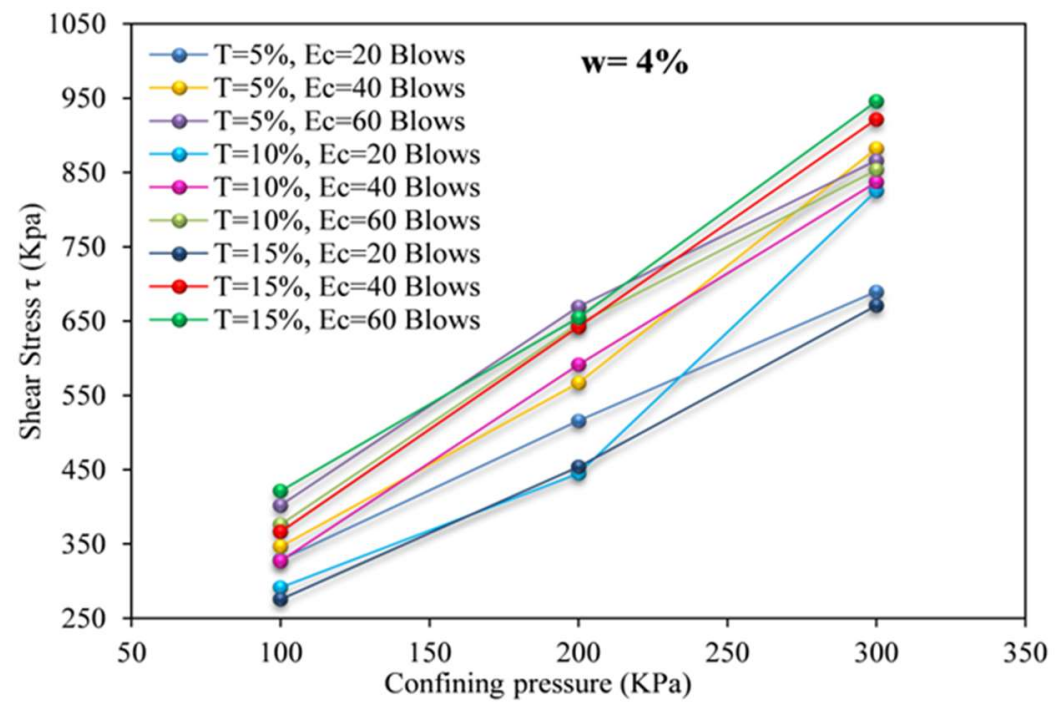

Fig.8. Effect of confining pressure on shear stress of specimens with varying treatment content and compaction energy

This increase in shear stress can be attributed to the stabilizer content in the presence of water. The hydration chemical reactions begin to appear between the clay and the CES on one hand, and between clay and CGBS on the other hand. These reactions may result due to the reinforcement of the particle bounds leading to a certain densification of the treated soil. In presence of clay, CES and CGBS, two components are produced, such as C-S-H and C-A-H which are responsible for the increase in shear stress, as shown in Fig.8.

On the other hand, one of the most important parameters to be studied is the effect of the deviator stress on the axial strain as shown in Fig. 9 in order to better understand the effectiveness of this type of treatment on the strength parameters of the collapsible soil. 

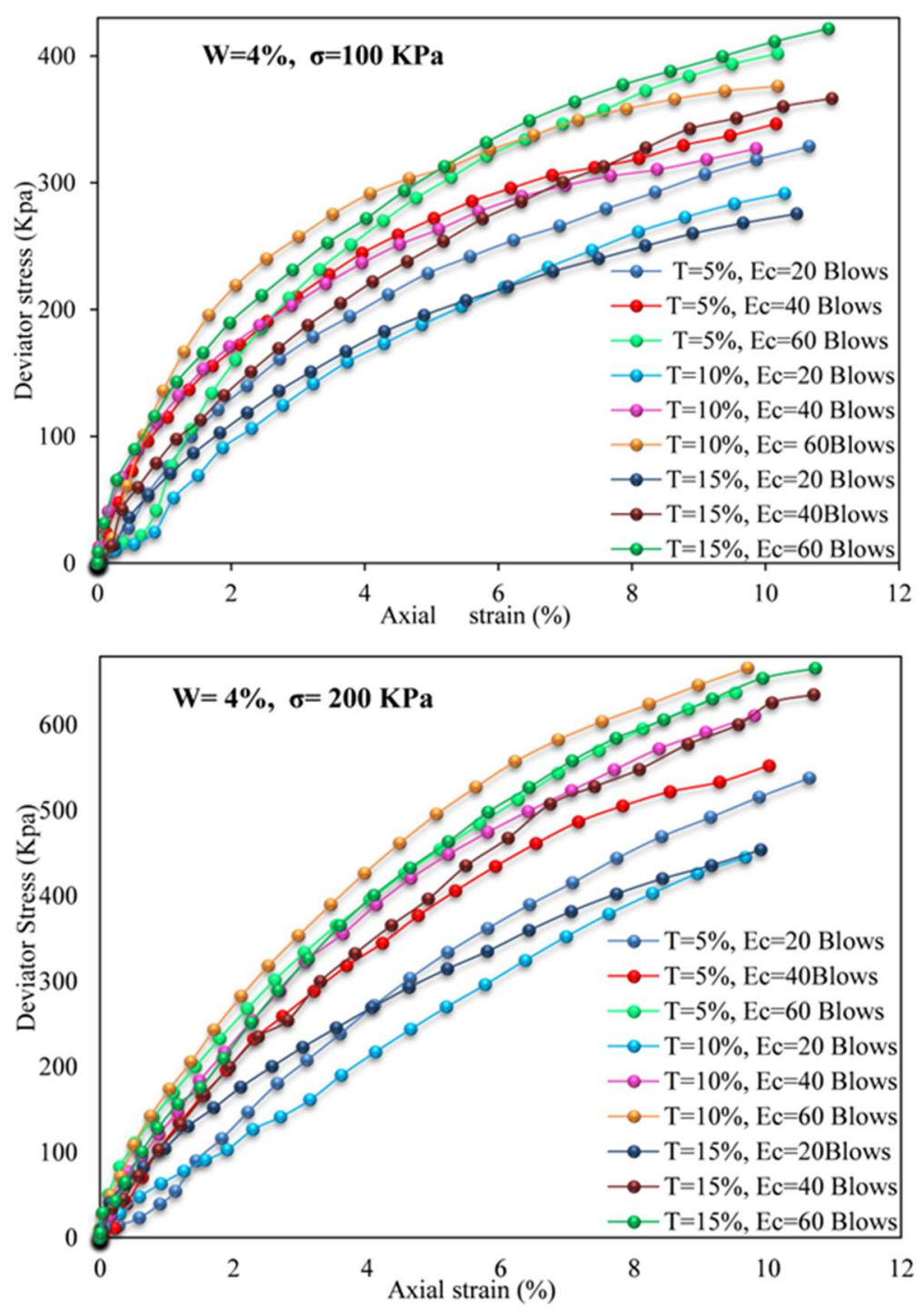


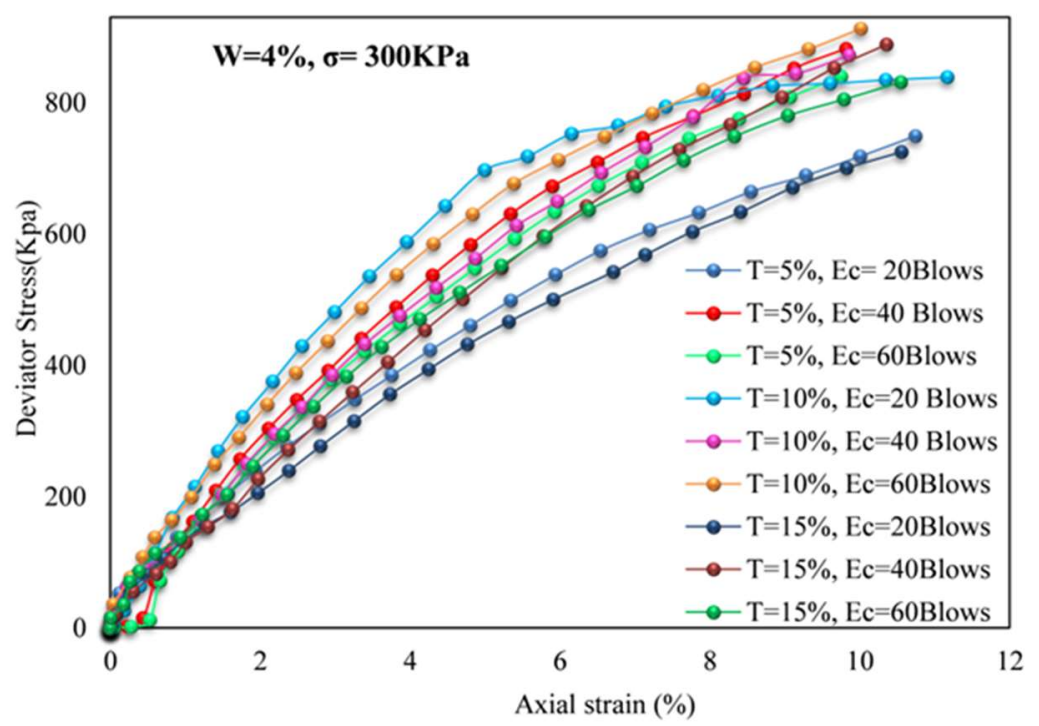

Fig.9. Effect of stabilizer content and energy compaction on deviator stress-Axial deformation behaviour

The deviator stress increases with increasing the stabilizer content and the compaction energy. The maximum deviator stress is reached with a stabilizer content of $15 \%$ and $\mathrm{Ec}=60$ blows/layer, as shown in Fig. 9. This is due to the flocculation of clay particles which is the main responsible of the increase in the shear stress of the soil. The existence of new cementitious materials due to chemical reactions which provid adhesive bonds in one side and the densification of soil in other side contributing to the increase in the deviator stress.

The main element of calcined eggshell is $\mathrm{CaO}$ as shown in Fig. 10, which increases the $\mathrm{PH}$ of the soil, so the hydraulic reaction can start. 


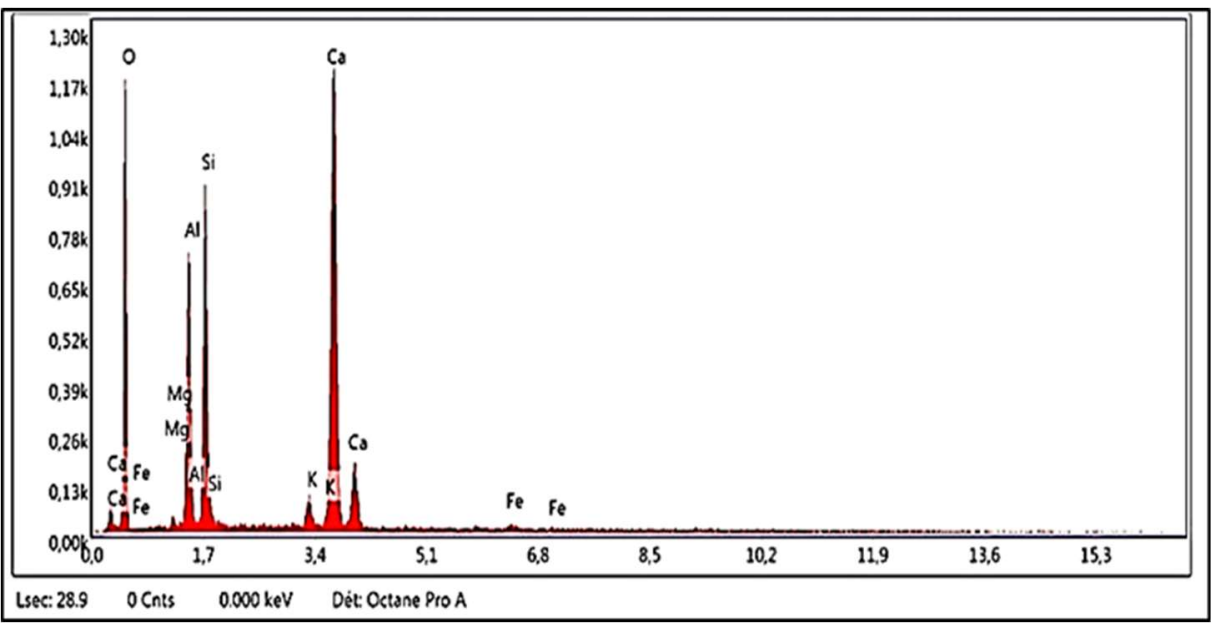

Fig10. Energy Dispersive X-ray Microanalysis (EDM) of treated soil with 15\% of stabilizer

These are reported by Nidzam and Kinuthia [34], and shown by the following reactions:

$$
\mathrm{CaO}+\mathrm{H}_{2} \mathrm{O} \rightarrow \mathrm{Ca}(\mathrm{OH})_{2}+\uparrow \mathrm{Heat}
$$

From the hydrated calcium and in presence of heat which participates in reducing the water content with vapour of water, the dissociation of hydroxide calcium further takes place as shown in equation(2).

$$
\mathrm{Ca}(\mathrm{OH}) \rightarrow \mathrm{Ca}^{2+}+2 \mathrm{OH}^{-}
$$

When positively charged calcium cations are formed from hydroxide calcium, an immediate cation exchange between the metallic ions combined with the surface of clay particles and the calcium provided from CES starts to occur. Therefore, the particles of clay flocculate and agglomerate this phenomenon is responsible for modifying the characteristics of treated soil $[42,44]$. According to Nidzam et al. and Milad et al. (2018) [45, 43], there is two reactions that produce the cementitious materials, namely pozzolanic reaction and hydration reaction, the association of calcium hydroxide of CES and water, with aluminate of kaolinite forms the adhesive bond $\mathrm{C}-\mathrm{A}-\mathrm{H}$, and the combination of calcium hydroxide with silicate forms C-S-H, as illustrated in the following reactions.

$$
\mathrm{Ca}^{2+} 2 \mathrm{OH}^{-}+\mathrm{Al}_{2} \mathrm{O}_{3} \rightarrow \mathrm{CaOAl}_{2} \mathrm{O}_{3}+\mathrm{H}_{2} \mathrm{O}
$$




$$
\mathrm{Ca}^{2+}+2 \mathrm{OH}^{-}+\mathrm{SiO}_{2} \rightarrow \mathrm{CaOSiO}_{2}+\mathrm{H}_{2} \mathrm{O}
$$

These results are reported by Nidzam et al. [34] who added the third reaction between the clay and CGBS particle. From the above findings, the increase in shear stress is a function of the increase in stabilizer content was explained.

\subsection{Microstructural analysis}

The stabilizer is considered to have a substantial effect on the chemical characteristics of the treated soil and the intensity of collapse potential. Scanning electron microscope is used to gain insight the behaviour of the mixture, to determine the morphology characteristics of the collapsible soil treated with the stabilizer and to develop the shape of intergranular bonds.

The effect of compaction energy on the collapse potential of the treated soil is shown in Fig.11(d) and Fig.12(h). It can be concluded that the CP decreases with increasing the number of blows/layer. This decrease in collapse potential is within the limits of $95 \%$.

It was increasingly recognized that the treatment of soil with CES content of $15 \%$ has decreased the collapse potential to $0.27 \%$ with a compaction energy corresponding to 60 blows/layer. Compacted soil at energy of 3 blows/ layer still have an open structure with a relatively high void ratio, facilitating the migration of fine particles from one level to another in the soil sample. When the soil is compacted with 60 blows/layer leading it to dense state, and the destruction of intergranular bonds and movement of fine particles become relatively difficult, also the increase in the friction between particles will increase the shear strength $[46,47]$. 

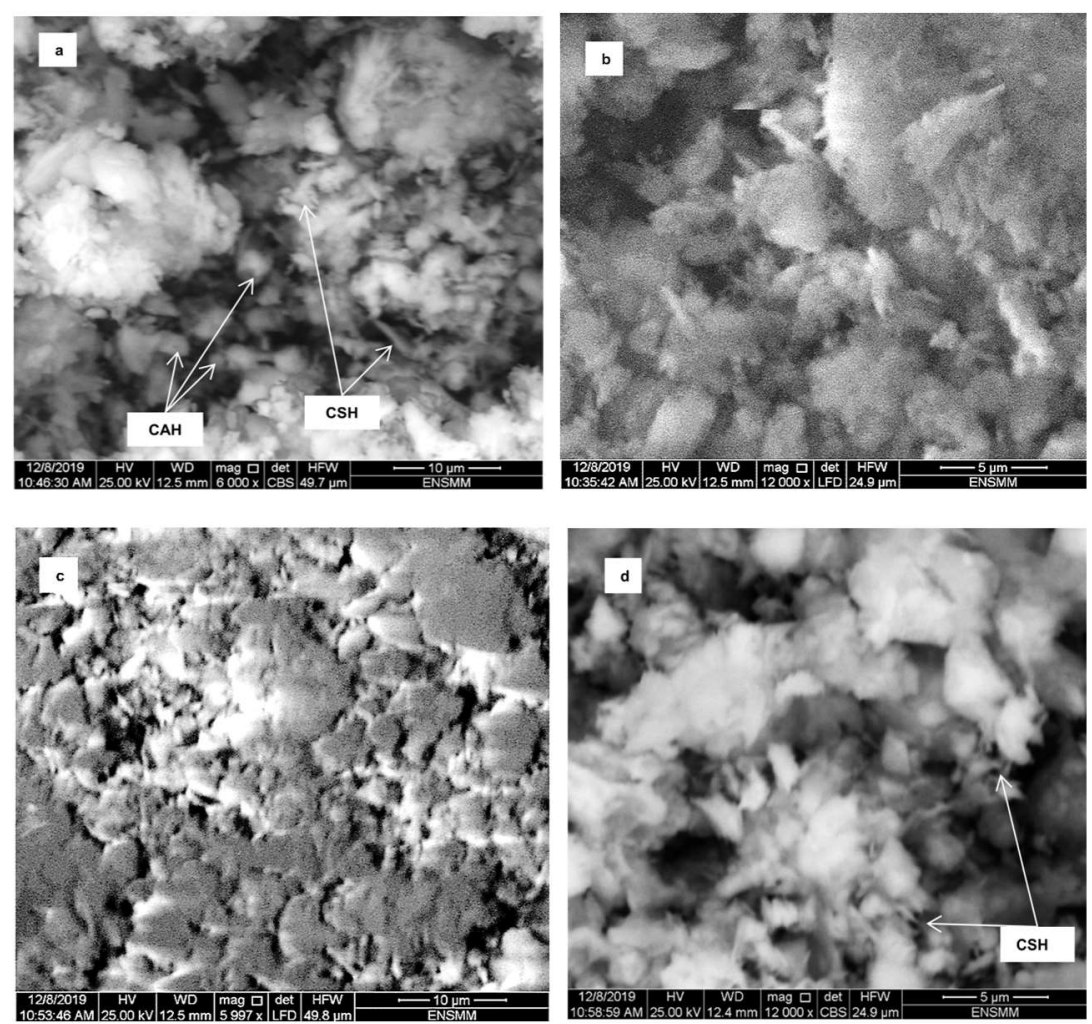

Fig.11. Scanning Electron Microscopy (SEM) and Energy Dispersive X-ray Microanalysis (EDM) of treated (a,b) 3 Blows/layer, (c,d) 60 Blows/layer 

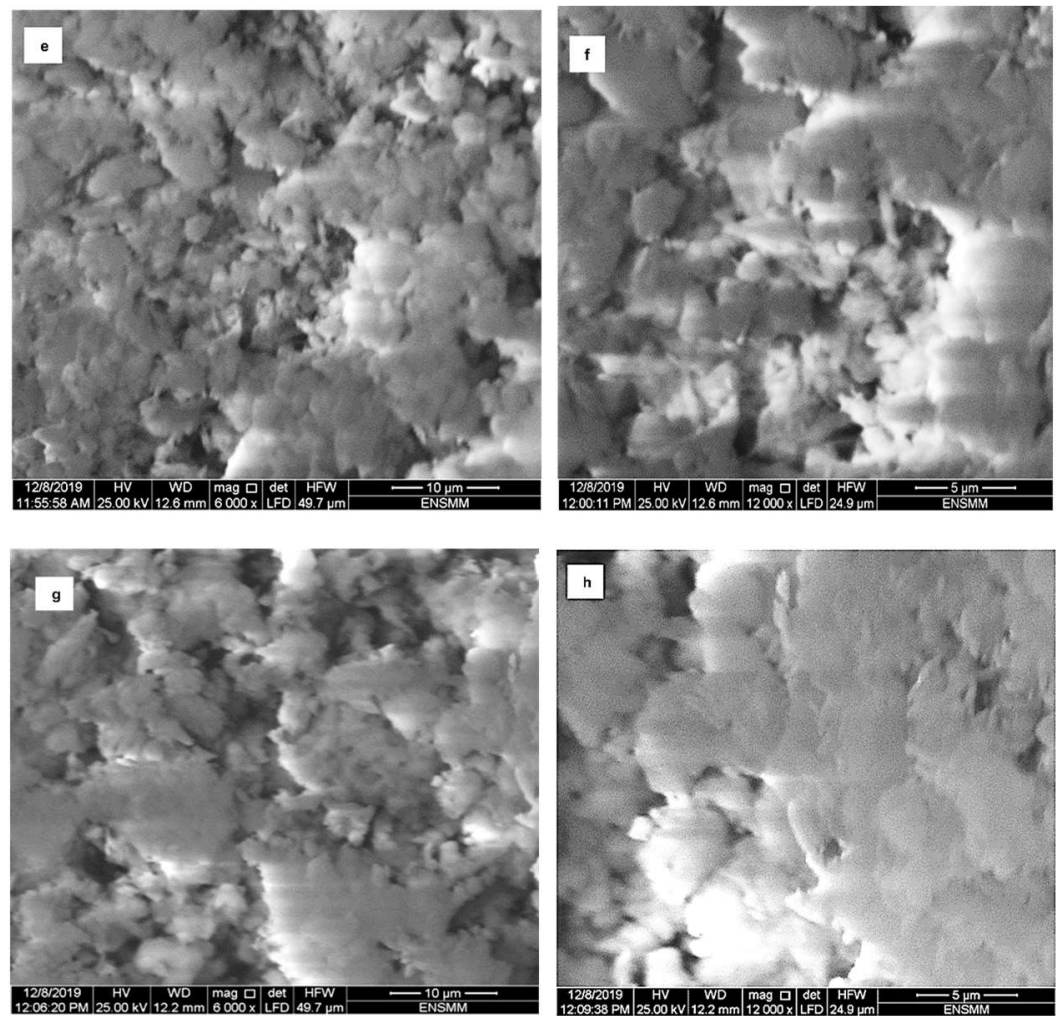

Fig.12. Scanning Electron Microscopy (SEM) and Energy Dispersive X-ray Microanalysis (EDM) of treated soil with 15\% of stabilizer e, f) 3 Blows/layer, g, h) 60 Blows/layer

Comparing figs. 11 and 12, the difference of number of agglomeration is clear, due to the formation of C-S-H and C-A-H. Furthermore, comparing fig. 11(b) with fig. 12(d), and fig. 12(f) with fig. 12(h), the effect of compaction energy is well observed.

\section{CONCLUSION}

The results of this study have shown that the calcined eggshell can replace the lime that contributes extensively to the reduction of the emission of the carbon dioxide. The CES-CGBS mixture has been found as a good technique to improve the mechanical characteristics of collapsible soil. This enhancement is significant in such a way that can achieve a non-collapsible soil. It increases the cohesion (c) 
and decreases the collapse potential (CP), but it has a small effect on the internal friction angle $(\varphi)$. The results have also indicated that this improvement is due to the presence of adhesive bonds ( $\mathrm{CSH}$ and $\mathrm{CAH})$ between particles in the matrix of treated soil. The use of $15 \%$ of stabilizer can decrease the collapse potential up to $95 \%$. In this study, it was also noticed that the use of low content of stabiliser can give an acceptable result, which proves the economic aspect of this stabilizer. The treatment of collapsible soil is depending on both initial water content and compaction energy, where the collapsibility of soil decreases when compaction energy is increased.

Eggshell and slag are found in the disposal of the waste and are harmful to the environment. To preserve our planet from these types of pollution agents, they can be used as treatment for collapsible soil.

Thus, sustainable development is achieved, by achieving a balance between the environmental, economic, social and technological system. In this context, our investigation in the treatment of collapsible was undertaken.

\section{Acknowledgements}

The authors would like to thank the LGCH laboratory of the University of 8th May 1945 of Guelma where the experimental work has been undertaken and the Metallurgical Unit of El Hadjar, in Annaba for providing Blast Furnace Slag.

\section{REFERENCES}

1. Reznik, YM 1995. Settlements of bearing plates on collapsible loessial soils. Environmental and Engineering Geoscience 1, 153-162.

2. Ayadat, T and Gherabli, A 1995. Traitement des sols affaissables par du ciment CPA. In: Annales de l'Institut technique du bâtiment et des travaux publics 530(SF-224), 33-44.

3. Ayadat, T, Dahili, M and Ahmed, KMH 1998. Traitement d'un sol effondrable par un liant hydrocarboné (bitume). Revue française géotechnique 85, 57-64.

4. Consoli, NC, Prietto, PDM and Ulbrich, LA 1998. Influence of fiber and cement addition on behavior of sandy soil. Journal geotechnical and geoenvironmental engineering 124, 1211-1214.

5. Yetimoglu T and Salbas, O 2003. A study on shear strength of sands reinforced with randomly distributed discrete fibers. Geotextiles and Geomembranes 21, 103-110.

6. Chauhan, MS, Mittal, S and Mohanty, B 2008. Performance evaluation of silty sand subgrade reinforced with fly ash and fibre. Geotextiles and geomembranes 26, 429-435. 
7. Ahmad, F, Bateni, F and Azmi, M 2010. Performance evaluation of silty sand reinforced with fibres. Geotextiles and geomembranes 28, 93-99.

8. Abbeche, K, Bahloul, O, Ayadat, T and Bahloul, A 2010.Treatment of collapsible soils by salts using the double consolidation method. Geotechnical Special Publication, Shanghai, China, 69-78.

9. Chegenizadeh, A and Nikraz, PH 2012. Study on Sand and paper reinforcement. International journal of emerging technology \& advanced engineering 2, 199-202.

10. Al Adili, A, Azzam, R, Spagnoli, G and Schrader, J 2012. Strength of soil reinforced with fiber materials (Papyrus). Soil Mechanics and Foundation Engineering 48, 241-247.

11. Mohamed, AMO and Gamal, MM 2012. Treatment of collapsible soils using sulfur cement. International Journal of Geotechnical Engineering 6, 65-77.

12. Ayadat, T and Hanna, AM 2012. Assessement of soil collapse prediction methods. International Journal of Engineering, Transactions B: Applications 25, 19-26.

13. Abdeldjouad, L, Asadi, A, Nahazanan, H, Huat, BBK, Dheyab, W and Elkhebu, AG 2019. Effect of Clay Content on Soil Stabilization with Alkaline Activation. International Journal of Geosynthetics and Ground Engineering 5, 167-174.

14. Zhang, M, Guo, H, El-Korchi, T, Zhang, G and Tao, M 2013. Experimental feasibility study of geopolymer as the next-generation soil stabilizer. Construction and Building Materials 47, 1468-1478.

15. Hambirao, GS and Rakaraddi, DPG 2014. Soil Stabilization Using Waste Shredded Rubber Tyre Chips. IOSR Journal of Mechanical and Civil Engineering 11, 20-27.

16. Fattah, MY, Al-Ani, MM and Al-Lamy, MTA 2014. Studying collapse potential of Gypseous soil treated by grouting. Soils and Foundations 54, 396-404.

17. Botero, E, Ossa, A, Sherwell, G and Ovando-Shelley, E 2015. Stress-strain behavior of a silty soil reinforced with polyethylene terephthalate (PET). Geotextiles and Geomembranes 43, 363-369.

18. Das, AP and Thyagaraj, T 2016. Effect of pore fluid on compressibility and collapse of clayey sand. Environmental Geotechnics 4, 432-443.

19. Sarsam, S, Al Saidi, A and Al Taie, A 2016. Assessment of shear and compressibility properties of asphalt stabilized collapsible soil. Applied research journal 2, 481-487.

20. Arabani, M and Lasaki, BA 2017. Behavior of a Simulated Collapsible Soil Modified with XPS-Cement Mixtures. Geotechnical and Geological Engineering 35, 137-155. 
21. Adjabi, S, Nouaouria, MS and Betehi, C 2018. Effect of reinforcement fibers on the collapse potential of clayey sands. 2nd International Congress on Materials \& Structural Stability - MATEC Web of Conferences, Morocco,15.

22. Kodicherla, SPK, Muktinuthalapati, J and Revanna, N 2018. Effect of randomly distributed fibre reinforcements on engineering properties of beach sand. Jordan Journal of Civil Engineering 12, 99-108.

23. Lv, Q, Chang, C, Zhao, B and Ma, B 2018. Loess Soil Stabilization by Means of $\mathrm{SiO}_{2}$ Nanoparticles. Soil Mechanics and Foundation Engineering 54, 409413.

24. Xing, $\mathrm{H}$ and Liu, L 2018. Field tests on influencing factors of negative skin friction for pile foundations in collapsible loess regions. International journal civil engineering 16, 1413-1422.

25. Bellil, S, Abbeche, K and Bahloul, O 2018. Treatment of a collapsible soil using a bentonite-cement mixture. Studia Geotechnica et Mechanica 40, 233 243.

26. Ziani, H, Abbèche, K, Messaoudene, I and Andrade Pais, L J 2019. Treatment of Collapsible Soils by Additions of Granulated Slag and Natural Pozzolan. KSCE Journal of Civil Engineering 23, 1028-1042

27. Maher, M, Ho, Y and Pincus, H 1993. Behavior of Fiber-Reinforced Cemented Sand Under Static and Cyclic Loads. Geotechnical Testing Journal 16, 330 .

28. Lee, SJ and Oh, SH 2003. Fabrication of calcium phosphate bioceramics by using eggshell and phosphoric acid. Materials Letters 57, 4570-4574.

29. Balázsi, C, Wéber, F, Kövér, Z, Horváth, E and Németh, C 2007. Preparation of calcium-phosphate bioceramics from natural resources. Journal of the European Ceramic Society 27, 1601-1606.

30. Wei, Z, Xu, C and Li, B 2009. Application of waste eggshell as low-cost solid catalyst for biodiesel production. Bioresource Technology 100, 2883-2885.

31. Bougara, A, Lynsdale, C and Ezziane, K 2009. Activation of Algerian slag in mortars. Construction and Building Materials 23, 542-547.

32. Behim, M, Cyr, M and Clastres, P 2011. Physical and chemical effects of El Hadjar slag used as an additive in cement-based materials. European Journal of Environmental and Civil Engineering 15, 1413-1432.

33. Lawton, EC, Fragaszy, R J and Hetherington, MD 1992. Review of wettinginduced collapse in compacted soil. Journal of Geotechnical and Geoenvironmental Engineering 118, 1376-1394

34. Novaouria, MS, Harireche, O and Rouaiguia, A 2002. Comportement de l'affaissement de loess. In: Annales du bâtiment et des travaux publics 3, 3741. 
35. Jennings, JE 1975. A guide to construction on or with materials exhibiting additional settlement due to collapse of grain structure. Proceedings of the 6th Regional Conference for Africa on Soil Mechanics and Foundation Engineering, Durban 99-105.

36. ASTM D2850, 03a (2007), Standard Test Methods for UnconsolidatedUndrained Triaxial Compression Test on Cohesive Soils. ASTM International, West Conshohocken.

37. Abbeche, K, Ayadat, T and Lahmadi A 2009. Traitement d'un sol á effondrement brusque par la chaux lime stabilisation of a collapsible soil. Séminaire International Innovation et Valorisation dans le Génie Civil, Hammamet, Tunisia, 161-168.

38. Firoozfar A and Dousti, M 2019. Kerman collapsible clay amendment by lime, bentonite, and nano silica. Magazine of Civil Engineering 90, 119-129.

39. Al Shaba, AA, Abdelaziz, TM and Ragheb, AM 2018. Treatment of collapsible soils by mixing with iron powder. Alexandria Engineering Journal 57, 3737-3745.

40. Iranpour, B 2016. The influence of nanomaterials on collapsible soil treatment. Engineering Geology 205, 40-53.

41. Bahloul, O, Abbeche, K, Bahloul, A and Halitim, A 2014. Effect of sodium chloride on the wetting induced collapse strain of soils. Malaysian Journal of Civil Engineering 26, 119-135.

42. Kinuthia, JM, Wild, S and Jones, GI 1999. Effects of monovalent and divalent metal sulphates on consistency and compaction of lime-stabilised kaolinite. Applied Clay Science 14, 27-45.

43. Nidzam RM and Kinuthia, JM 2010. Sustainable soil stabilisation with blastfurnace slag-a review. Proceedings of Institution of Civil Engineers: Construction Materials 163, 157-165.

44. Sherwood, P 1993. Soil stabilization with cement and lime. London: Her Majesty Stationary Office.

45. Tajdini, M, Bonab, MH and Golmohamadi, S 2018. An experimental investigation on effect of adding natural and synthetic fibres on mechanical and behavioural parameters of soil-cement materials. International journal civil engineering 16, 353-370.

46. Huat, BBK, Aziz, AA, Ali, FH and Azmi, NA 2008. Effect of wetting on collapsibility and shear strength of tropical residual soils. Electronic Journal of Geotechnical Engineering 13, 1-44.

47. Sathonsaowaphak, A, Chindaprasirt, P and Pimraksa, K 2009. Workability and strength of lignite bottom ash geopolymer mortar. Journal of Hazardous Materials 168, 44-50.

Editor received the manuscript: 11.07.2020 